\title{
Correction to: Improvement of analgesic efficacy for total hip arthroplasty by a modified ultrasound-guided supra-inguinal fascia iliaca compartment block
}

Ting Zheng ${ }^{1,2}$, Bin Hü ${ }^{2}$, Chun-ying Zheng ${ }^{1,2}$, Feng-yi Huang ${ }^{1,2}$, Fei Gao ${ }^{1,2}$ and Xiao-chun Zheng ${ }^{1,2,3^{*}}$

\author{
Correction to: BMC Anesthesiol 21, 75 (2021) \\ https://doi.org/10.1186/s12871-021-01296-8
}

Following publication of the original article [1], the authors reported an error in: the authors' institution and the Fig. 2 has a minor adjustment. Because Our author's institution has recently made a change, so I must to replace all the authors' institution as follow:

1 Shengli Clinical Medical College of Fujian Medical University, Fuzhou, Fujian, China

2 Department of Anaesthesiology, Fujian Provincial Hospital, Fuzhou, China

3 Fujian Emergency Medical Center, Fuzhou, China

\section{Author details}

'Shengli Clinical Medical College of Fujian Medical University, Fuzhou, Fujian,

China. ${ }^{2}$ Department of Anaesthesiology, Fujian Provincial Hospital, Fuzhou,

China. ${ }^{3}$ Fujian Emergency Medical Center, Fuzhou, China.

Published online: 31 March 2021

\section{Reference}

1. Zheng T, Hu B, Zheng C, et al. Improvement of analgesic efficacy for total hip arthroplasty by a modified ultrasound-guided supra-inguinal fascia iliaca compartment block. BMC Anesthesiol. 2021;21:75 https://doi.org/10.1186/ s12871-021-01296-8.

The original article can be found online at https://doi.org/10.1186/s12871 021-01296-8.

* Correspondence: zhengxiaochun7766@163.com

'Shengli Clinical Medical College of Fujian Medical University, Fuzhou, Fujian, China

${ }^{2}$ Department of Anaesthesiology, Fujian Provincial Hospital, Fuzhou, China

Full list of author information is available at the end of the article

C C The Author(s). 2021 Open Access This article is licensed under a Creative Commons Attribution 4.0 International License, which permits use, sharing, adaptation, distribution and reproduction in any medium or format, as long as you give appropriate credit to the original author(s) and the source, provide a link to the Creative Commons licence, and indicate if changes were made. The images or other third party material in this article are included in the article's Creative Commons licence, unless indicated otherwise in a credit line to the material. If material is not included in the article's Creative Commons licence and your intended use is not permitted by statutory regulation or exceeds the permitted use, you will need to obtain permission directly from the copyright holder. To view a copy of this licence, visit http://creativecommons.org/licenses/by/4.0/ The Creative Commons Public Domain Dedication waiver (http://creativecommons.org/publicdomain/zero/1.0/) applies to the data made available in this article, unless otherwise stated in a credit line to the data. 


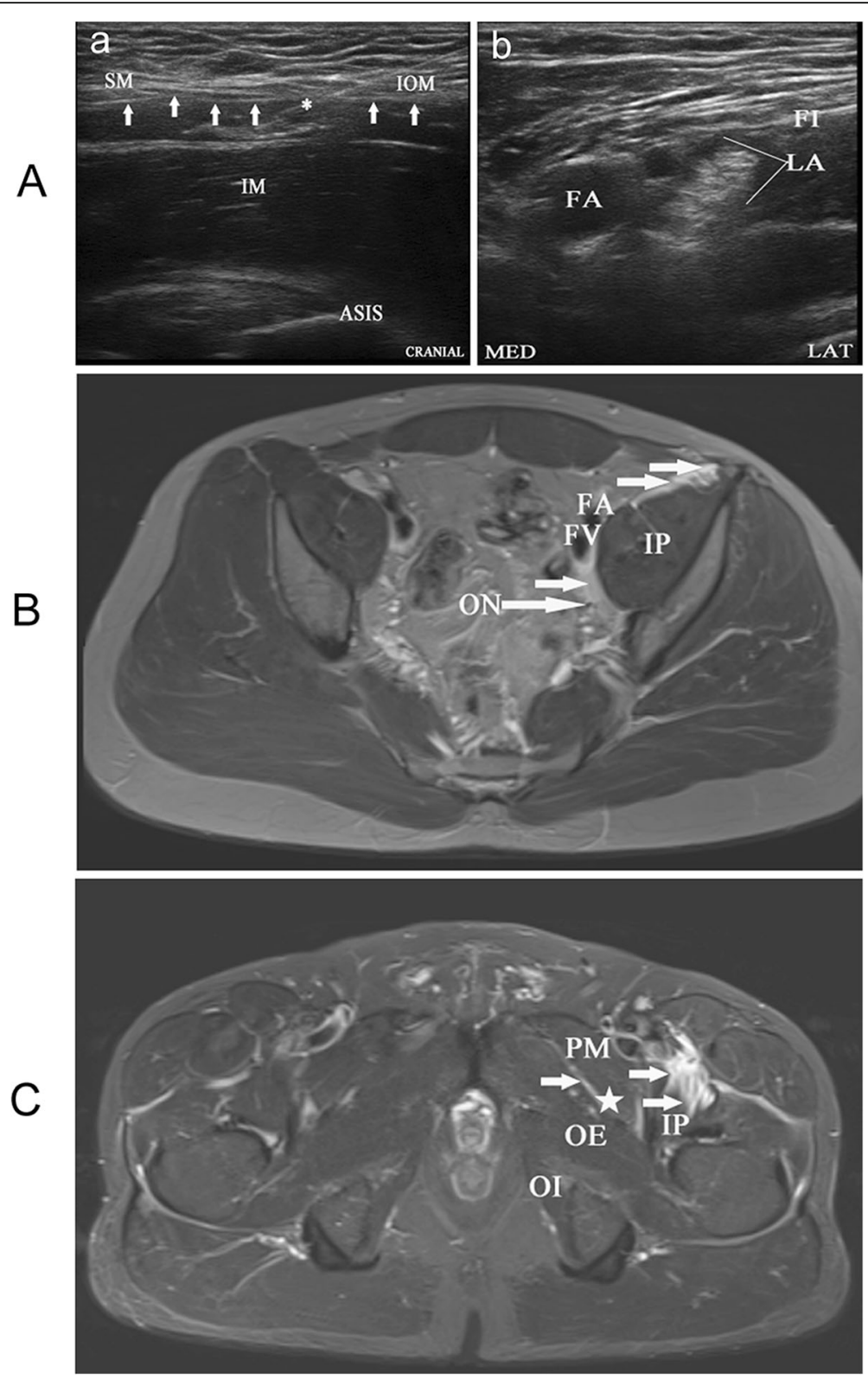

Fig. 2 Ultrasound and magnetic resonance images. a. Ultrasound images of a novel suprainguinal fascia iliaca compartment block (FICB). (a) Ultrasound image for identification of the relevant structures for FICB. White arrows, fascia iliaca; *, needle; ASIS, anterior superior iliac spine; SM, sartorius muscle; IOM, internal oblique muscle; IM, iliac muscle; (b) local anesthetic around the FN. Fl, fascia iliaca; FN, femoral nerve; FA, femoral artery; MED, medial; LAT, lateral. b. An axial T2- weighted fat-suppressed magnetic resonance image at the level of the fourth sacral vertebra shows medial spread of injectate (small white arrows) in a plane superficial to the IP muscle and deep to the FA and FV. IP: iliopsoas; ON: obturator nerve; FA: femoral artery; FV: femoral vein. c. An axial T2-weighted fatsuppressed magnetic resonance image at the level of the second coccygeal vertebra shows medial spread of injectate (white arrows) in a plane superficial to the IP muscle and diffuses below the pectineus muscle to obturator nerve ( $(\hat{\xi})$. PM: pectineus muscle; IP: iliopsoas; OE: obturator externus; Ol: obturator internus 